\title{
Verification of RAP Model Soundings in Preconvective Environments
}

\author{
JENNIFER M. LAFLIN \\ NOAA/National Weather Service, Kansas City/Pleasant Hill, Missouri
}

(Manuscript received 11 February 2013; in final form 30 April 2013)

\begin{abstract}
While mesoscale models have a strong utility in severe convective weather forecasting, errors or biases in these models can hinder their ability to resolve environments conducive to convection, and may alter forecasters' perception of the probability of severe weather. During the 2012 spring convective season, a low bias in both low-level moisture and convective available potential energy (CAPE) forecasts were observed at six locations across the Great Plains in model forecasts from the Rapid Refresh (RAP). These errors may be attributed at least in part to the planetary boundary layer scheme and the assimilation of surface conditions of the RAP, and tend to occur in fairly dry, well-mixed environments. Forecasters should be aware of these errors when determining the likelihood of severe weather in such environments, and should compare RAP solutions to other model output with differing configurations, like the experimental RAP (RAPv2) run at the Earth System Research Laboratory, the High Resolution Rapid Refresh (HRRR), and locally run mesoscale models.
\end{abstract}

\section{Introduction}

In anticipation of severe convective weather, forecasters often rely on model forecast soundings and derived parameters to determine both the likelihood of convective initiation and the potential severity of any storms that develop. Model solutions are highly dependent on the data assimilation scheme, physics, and parameterizations used; thus, forecast soundings and their derived parameters can vary greatly between differing numerical model configurations. On 1 May 2012, the National Centers for Environmental Prediction (NCEP) implemented the operational Rapid Refresh (RAP; Benjamin et al. 2007) model, which is a replacement for the Rapid Update Cycle (RUC; Benjamin et al. 2004) model. Due to its relatively high spatial and temporal resolution, the RAP is potentially a useful tool for severe convective weather forecasting, and is also used to create the Storm Prediction Center (SPC)'s mesoanalysis graphics (Bothwell et al. 2002); as a result, it is important for operational forecasters to know how the RAP performs in preconvective environments. This study examines the performance of RAP forecast soundings and instability parameters during the 2012 spring convective season, and seeks to identify environments and situations which may lead to particularly poor model forecasts.

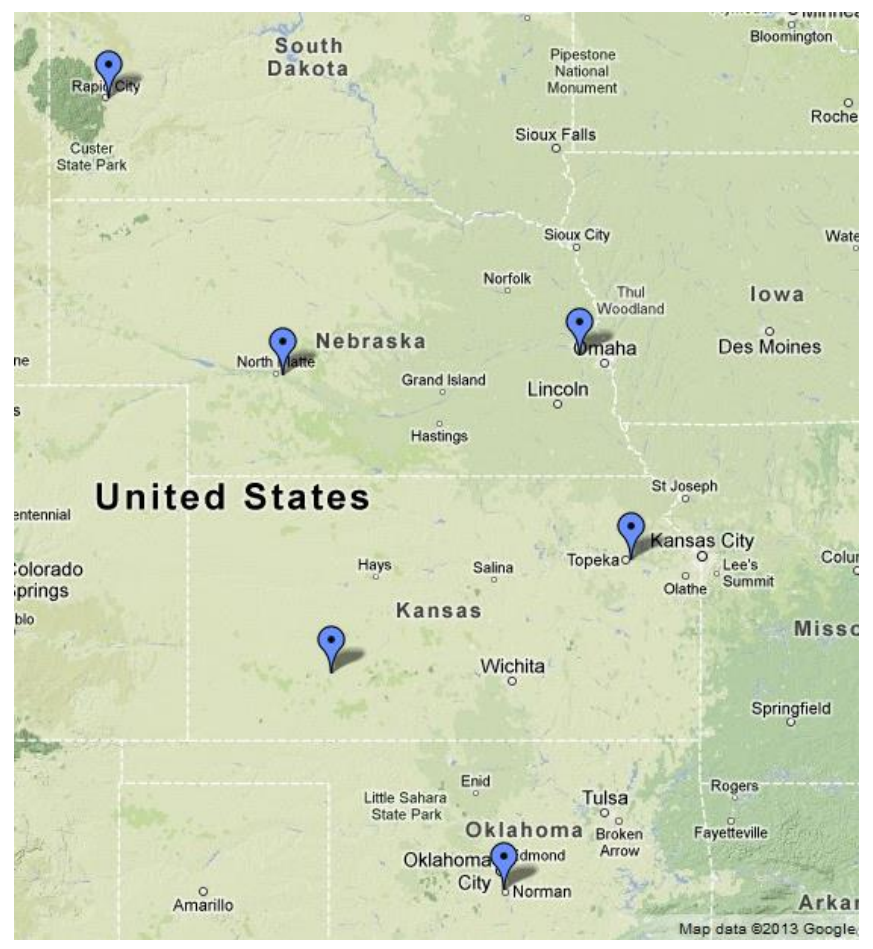

Figure 1. Location of all six rawinsonde sites used in this study: Rapid City, SD (KRAP), North Platte, NE (KLBF), Omaha/Valley, NE (KOAX), Dodge City, KS (KDDC), Topeka, KS (KTOP), and Norman, OK (KOUN). Click image for an external version; this applies to all figures hereafter. 


\section{Data and methods}

To evaluate the performance of the RAP, 12- and 6-h model forecast soundings from the 1200 and 1800 UTC model runs (respectively) were compared to 0000 UTC soundings from six rawinsonde locations: Rapid City, South Dakota (KRAP), North Platte, Nebraska (KLBF), Omaha/Valley, Nebraska (KOAX), Dodge City, Kansas (KDDC), Topeka, Kansas (KTOP), and Norman, Oklahoma (KOUN; Fig. 1). All 0000 UTC soundings from these locations between 2 May-15 July 2012 were filtered using the following criteria: 1) $100-\mathrm{hPa}$ mean-layer convective available potential energy (MLCAPE) greater than $500 \mathrm{~J} \mathrm{~kg}^{-1}, 2$ ) site location within the SPC Day 11300 UTC Convective Outlook for thunderstorms, and 3) no obvious contamination from the activation of the model's deep convective parameterization, which was determined by visually examining temporal trends in the moisture and temperature profiles using the Buffalo Toolkit for Lake Effect Snow (BUFKIT; Mahoney and Niziol 1997), and by identifying where and when convective precipitation was produced by the model. These criteria were selected in order to focus on environments in which convective initiation was possible, and to eliminate data quality issues associated with model convection. In total, 56 cases met the aforementioned criteria and were used for RAP model sounding verification. Model performance was qualitatively evaluated by examining the vertical profiles of temperature and moisture, and was quantified by an analysis of surface-based (SB), mostunstable (MU), and MLCAPE.

Table 1. Total error from the 1200 UTC 12-h and 1800 UTC 6-h RAP forecasts of SBCAPE, MUCAPE, and MLCAPE, and the average of the 1200 UTC and 1800 UTC forecast error. The total error is calculated by subtracting observed 0000 UTC CAPE from the RAP forecast CAPE, and is averaged over 46 cases. Negative errors denote under-forecasts by the RAP model.

\begin{tabular}{|c|c|c|c|}
\hline Errors & 1200 UTC & 1800 UTC & Average \\
\hline SBCAPE $\left(\mathrm{J} \mathrm{kg}^{-1}\right)$ & -1115 & -957 & -1036 \\
\hline MUCAPE $\left(\mathrm{J} \mathrm{kg}^{-1}\right)$ & -1175 & -1017 & -1096 \\
\hline MLCAPE $\left(\mathrm{J} \mathrm{kg}^{-1}\right)$ & -498 & -346 & -422 \\
\hline
\end{tabular}

\section{Analysis}

Of the 56 observed soundings, CAPE was underforecast by both the 1200 and 1800 UTC RAP in 46 ( $82 \%)$ of the cases, which can be qualitatively shown by comparing forecast versus observed CAPE values to a perfect forecast=observed line (Fig. 2). Underestimation was notable - average total errors for these 46 cases were $-1036 \mathrm{~J} \mathrm{~kg}^{-1}$ for SBCAPE, -1096 $\mathrm{J} \mathrm{kg}^{-1}$ for MUCAPE, and $-422 \mathrm{~J} \mathrm{~kg}^{-1}$ for MLCAPE (Table 1). For perspective, mean observed SBCAPE, MUCAPE, and MLCAPE values were $2228 \mathrm{~J} \mathrm{~kg}^{-1}$, $2288 \mathrm{~J} \mathrm{~kg}^{-1}$, and $1411 \mathrm{~J} \mathrm{~kg}^{-1}$, respectively, meaning a $30-50 \%$ error on average (Fig. 3). The Student's $t$-test was also performed on the 1200 UTC and 1800 UTC RAP forecasts, and revealed that the difference between the observed and forecast CAPE is less than zero at the $99 \%$ confidence level.
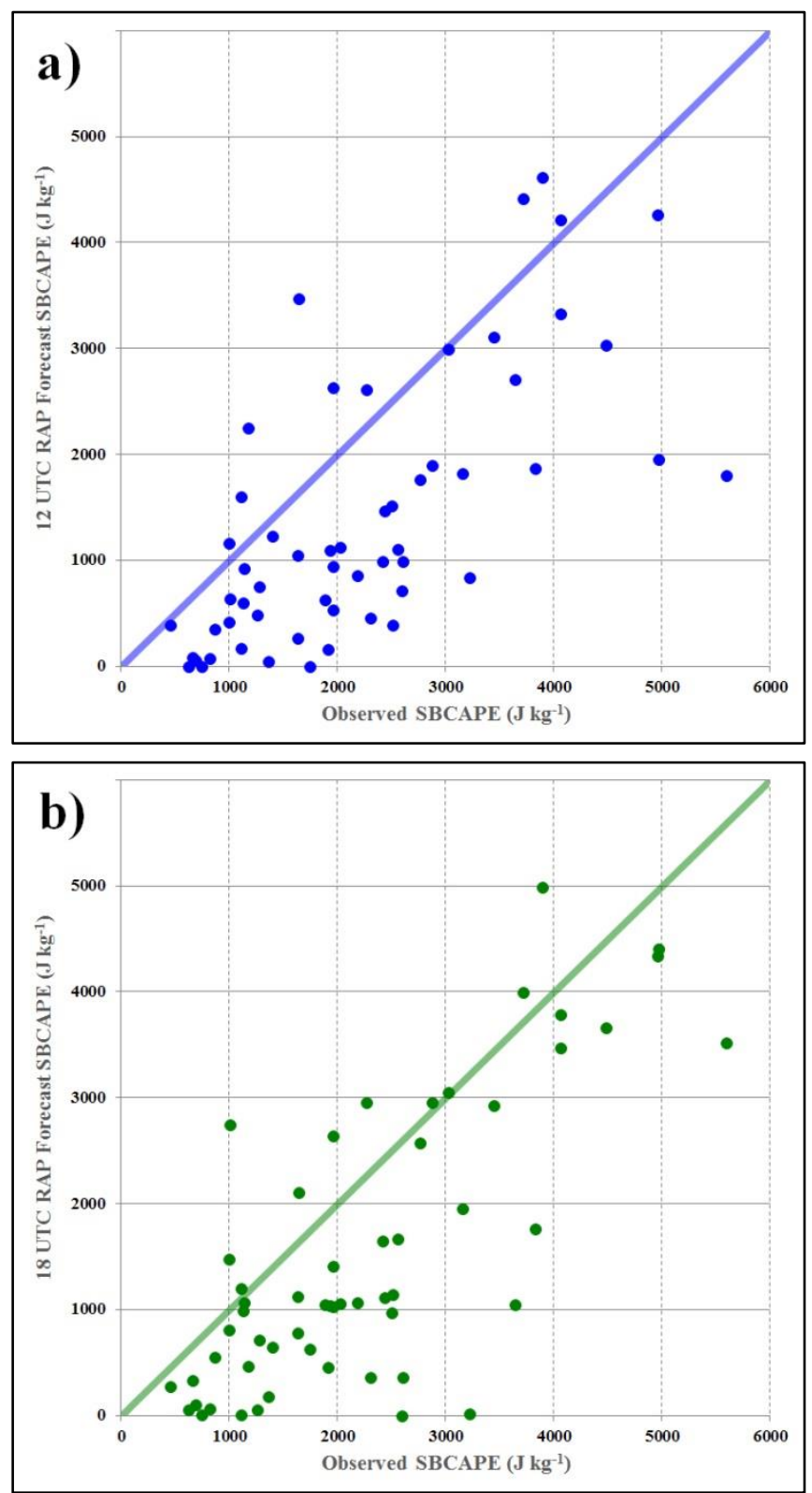

Figure 2. Scatter plot of observed (x-axis) versus forecast (y-axis) SBCAPE from the (a) 1200 UTC RAP model and (b) 1800 UTC RAP model, both valid at 0000 UTC. The blue line in (a) and green line in (b) indicates the situation where forecast=observed. 


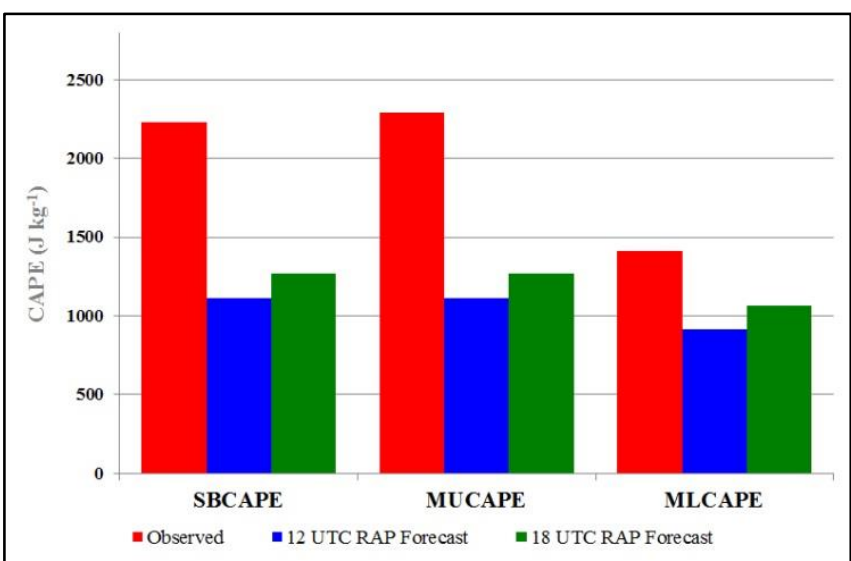

Figure 3. Average SB, MU, and MLCAPE for observed (red), 1200 UTC RAP model forecast (blue), and 1800 UTC RAP model forecast (green) for the 46 cases where CAPE was under-forecast by the RAP.

To better identify the origination of these significant errors in CAPE forecasts, forecast soundings were overlaid on the observed soundings for the four worst forecasts (largest relative error for SBCAPE) using the Universal RAwinsonde OBservation program (RAOB, Shewchuk 2002). Figure 4 highlights a dry bias in boundary layer moisture for all four soundings, leading to a higher forecast lifted condensation level and lower CAPE. Only small errors in the temperature forecast are indicated in Fig. 4, which may be a result of the adherence of the observed temperature profile to the dry adiabatic lapse rate. Observed and forecast SBCAPE and convective inhibition (SBCIN) also are displayed in Fig. 4, quantifying the model forecast errors. It is important to note that convective initiation occurred after 0000 UTC in all four cases; however, the very low forecast values of CAPE may have caused forecasters not to anticipate convection, and the RAP model also failed to activate its convective parameterization.
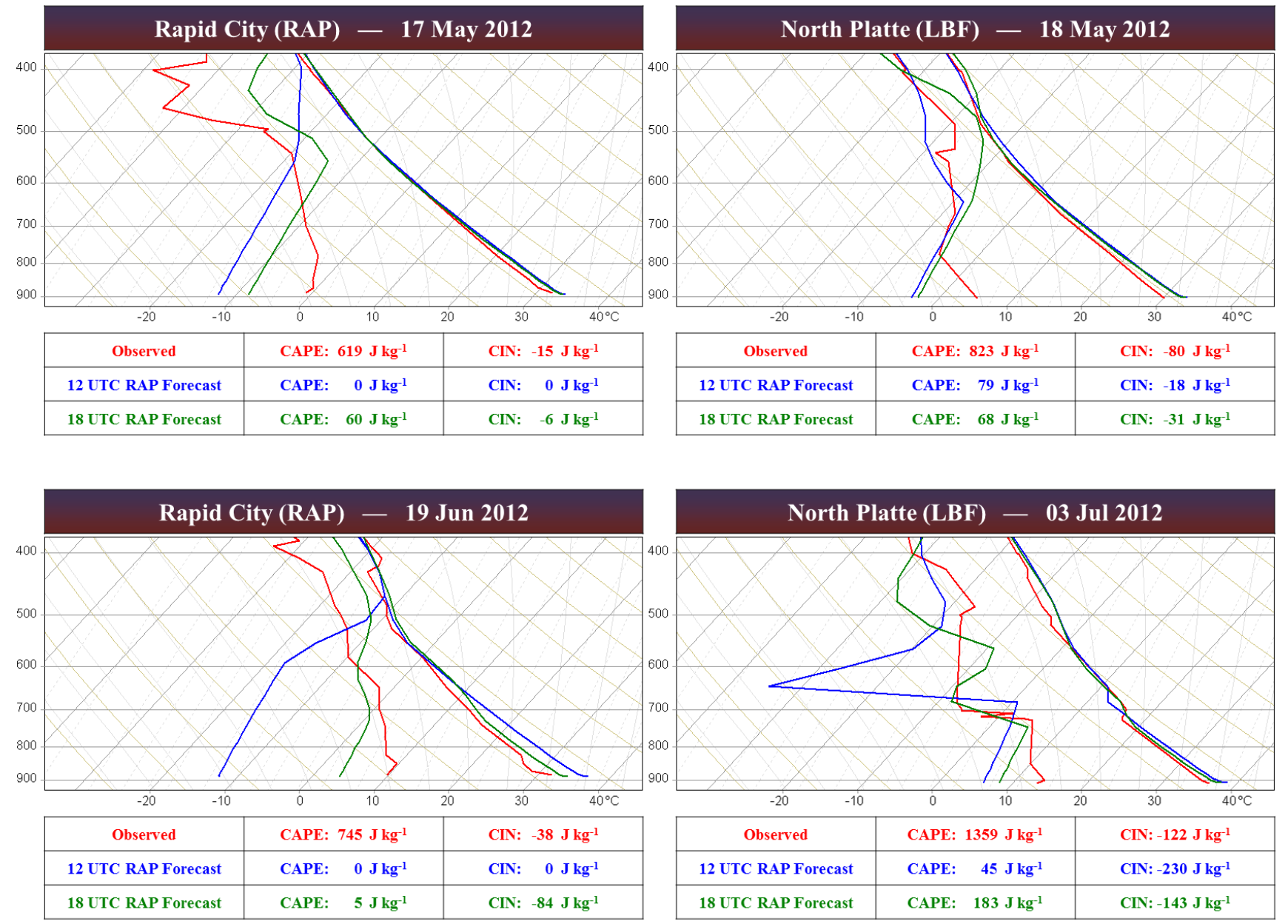

Figure 4. Forecast and observed soundings for the four worst RAP forecasts, and forecast and observed values of surface-based CAPE and CIN, valid at 0000 UTC on the date listed. Observed soundings and values are in red, 1200 UTC RAP forecast soundings and values are in blue, and 1800 UTC forecast soundings and values are in green. 


\section{Sounding Composite: Four Worst Forecasts}

\section{Sounding Composite: Four Best Forecasts}
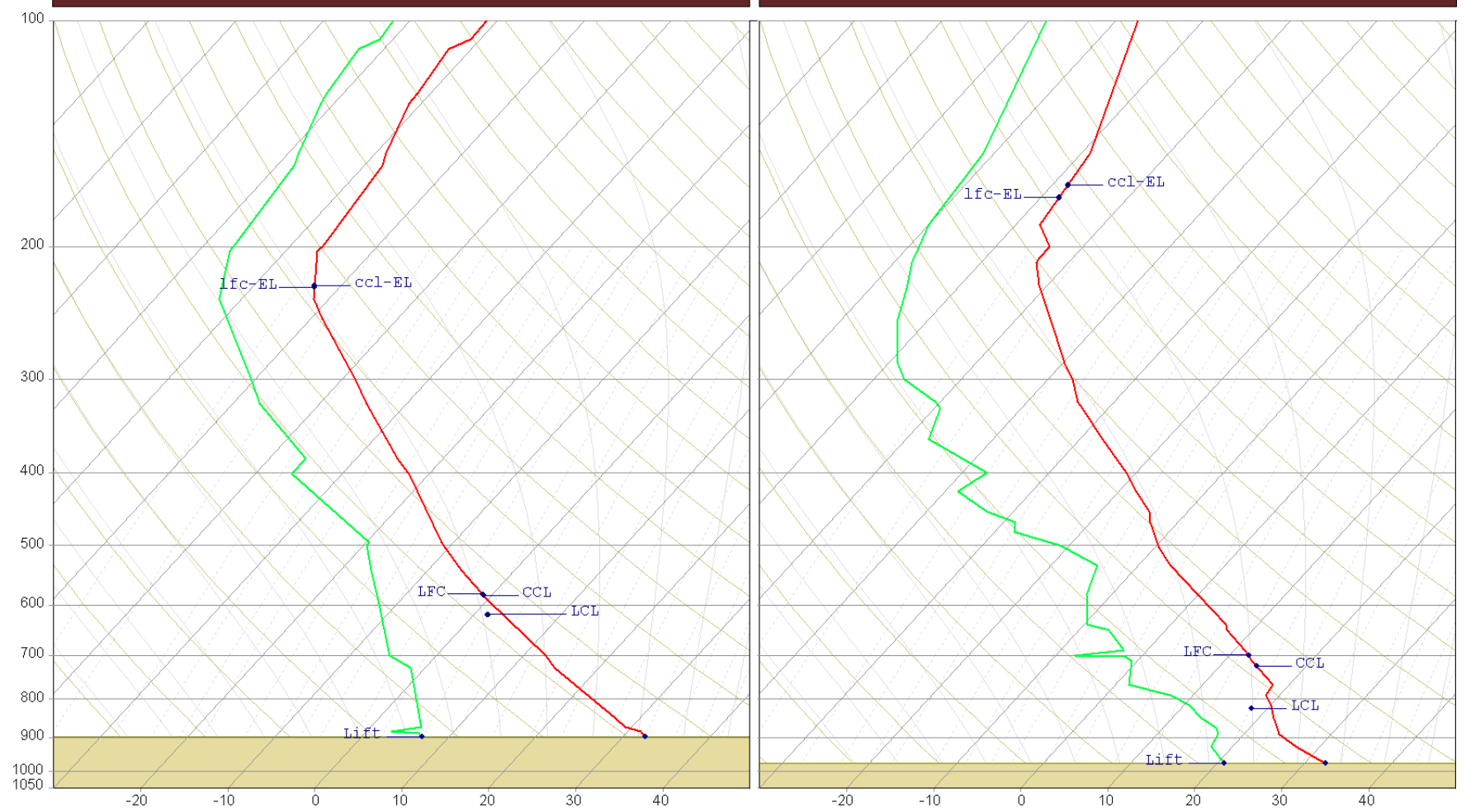

Figure 5. Composite of 0000 UTC observed soundings for the four worst forecasts (left) and the four best forecasts (right). Surfaced-based lifted condensation level (LCL), level of free convection (LFC), convective condensation level (CCL), and the equilibrium level for the LFC (lfc-EL) and the CCL (ccl-EL) are marked in blue.

Also of note are the overall temperature and moisture profiles of the observed soundings in Fig. 4. Qualitatively, the four cases in Fig. 4 are similar in the boundary layer; all are generally dry and feature steep lapse rates originating at the surface. In order to highlight the similarities in these soundings, composite 0000 UTC observed soundings for the four worst forecasts listed in Fig. 4 and the four best forecasts (smallest relative error for SBCAPE; not shown) were created (Fig. 5). Considerable differences are apparent between the environments that were well versus poorly forecast. Those that were most poorly forecast are much warmer and drier, and have a deeper boundary layer, compared to those that were well forecast. Since all four worst forecasts resulted in forecast CAPE values that were much too low, these results suggest that a dry environment with steep low-level lapse rates, similar to that depicted in the left panel of Fig. 5, will not be adequately resolved by the RAP and may provide poor guidance to operational forecasters. This is also illustrated in Fig. 6, which compares percent error in SBCAPE forecasts with the observed surface dewpoint depression at 0000 UTC; the overall trend is for the error to become larger (more negative) as the dewpoint depression increases, again indicating that the largest errors tend to occur in dry, well-mixed environments.

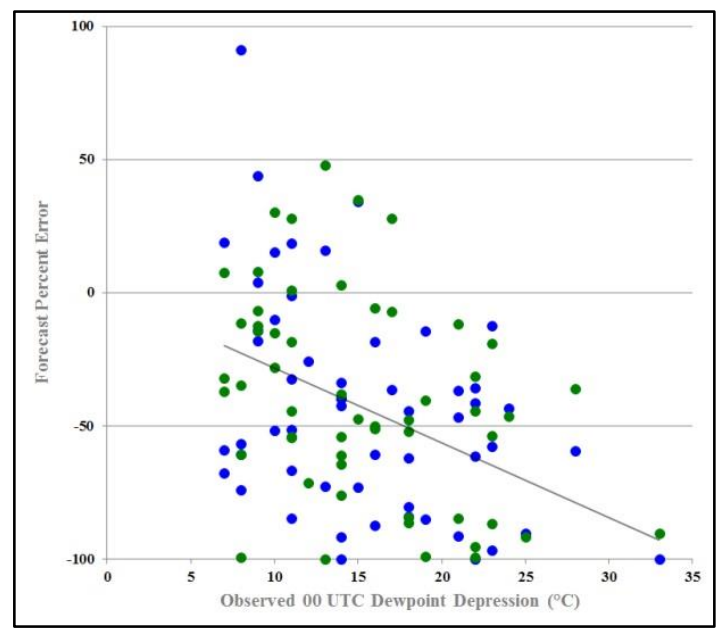

Figure 6. Scatter plot of observed dewpoint depression at 0000 UTC (x-axis) versus forecast percent error for SBCAPE by the 1200 UTC RAP model (blue) and the 1800 UTC RAP model (green). The gray line is a linear trendline fitted to both the 1200 UTC and 1800 UTC datasets. 


\section{Discussion}

Errors in the representation of near-surface moisture by the RAP have been noted by the Global Systems Division (GSD) of the NOAA Earth System Research Laboratory, leading to several updates in a new version of the RAP (version 2; hereafter, RAPv2). Those that are relevant to the issues discussed in this study include an improved assimilation of surface observations which impacts moisture throughout the boundary layer, and a change in the planetary boundary layer (PBL) scheme from Mellor-YamadaJanjic (MYJ; Janjic 2001) to Mellor-Yamada Nakanishi Niino (MYNN; Nakanishi and Niino 2004), as described by Weygandt et al. (2012). A recent study by $\mathrm{Hu}$ et al. (2010) indicates that the MYJ PBL scheme may be the least accurate scheme available for use in the Weather Research and Forecasting (WRF) model, and is not appropriate for unstable flows. Additionally, it is likely that the older surface observation assimilation method (without the moisture impacts throughout the boundary layer) and the PBL scheme used in the currently operational RAP are at least in part responsible for the errors identified herein, since marked improvement was seen using RAPv2 in cases highlighted by Weygandt et al. (2012). Although not currently available to operational forecasters through NCEP, RAPv2 (which, along with the HRRR, now also includes the MYNN PBL scheme) is available for viewing online (rapidrefresh.noaa.gov) and is used to initialize the HRRR, another potentially useful tool for severe convective weather forecasting.

\section{Conclusions}

During the 2012 spring convective season, RAP model forecasts significantly underestimated buoyancy on several occasions, primarily as a result of errors in forecast boundary layer moisture. In the cases examined, the average underestimation of CAPE was on the order of $1000 \mathrm{~J} \mathrm{~kg}^{-1}$, and such large errors could cause forecasters to underestimate the probability and severity of deep convection, especially in moderate- to low-CAPE environments. The largest errors tended to occur in dry, unstable environments with a deep, wellmixed boundary layer, where RAP model forecasts underestimated the magnitude of boundary layer moisture, causing a higher forecast LCL and lower forecast CAPE than was observed. As a result, forecasters should be skeptical of the boundary layer moisture profile in RAP forecasts soundings when deep, well-mixed boundary layers are anticipated.
Knowledge of these biases and comparison of RAP model solutions to other models with different configurations such as the HRRR, NAM, and locally run mesoscale model output, in addition to future improvements to the RAP, will aid forecasters in decision-making when severe weather is possible.

Acknowledgements. Thank you to Albert Pietrycha and Scott Blair (NWS Kansas City/Pleasant Hill), James Correia (CIMMS/NSSL), Phil Schumacher (NWS Sioux Falls), Jeff Manion (NWS Central Region Headquarters), and two anonymous reviewers for their input, reviews, and technical edits.

\section{REFERENCES}

Benjamin, S. G., and Coauthors, 2004: An hourly assimilationforecast cycle: the RUC. Mon. Wea. Rev., 132, 495-518.

Benjamin, S. G., and Coauthors, 2007: From radar-enhanced RUC to the WRF-based Rapid Refresh. Preprints, 18th Conf. on Numerical Weather Prediction, Park City, UT, Amer. Meteor. Soc., J3.4. [Available online at ams.confex.com/ams/pdfpapers/124827.pdf.]

Bothwell, P. D., J. A. Hart, and R. L. Thompson, 2002: An integrated three-dimensional objective analysis scheme in use at the Storm Prediction Center. Preprints, 21st Conf. on Severe Local Storms, San Antonio, TX, Amer. Meteor. Soc., JP3.1. [Available online at ams.confex.com/ams/ pdfpapers/47482.pdf].

$\mathrm{Hu}$, X., J. W. Nielsen-Gammon, and F. Zhang, 2010: Evaluation of three planetary boundary layer schemes in the WRF model. J. Appl. Meteor. Climatol, 49, 18311844.

Janjic, Z. I., 2001: Nonsingular implementation of the MellorYamada level 2.5 scheme in the NCEP Meso model. NCEP Office Note No. 437, 61 pp. [Available at www.emc.ncep.noaa.gov/officenotes/newernotes/on437.pdf.]

Mahoney, E. A., and T. A. Niziol, 1997: BUFKIT: A software application toolkit for predicting lake effect snow. Preprints, 13th International Conf. on Interactive Information and Processing Systems (IIPS) for Meteorology, Oceanography, and Hydrology, Long Beach, CA, Amer. Meteor. Soc., 388-391.

Nakanishi, M., and H. Niino, 2004: An improved MellorYamada level-3 model with condensation physics: Its design and verification. Bound.-Layer Meteor., 112, 1-31.

Shewchuk, J., 2002: RAOB (the Rawinsonde Observation Program) for Windows. Environmental Research Services. [Available online at www.raob.com.]

Weygandt, S. S., C. R. Alexander, E. P. James, M. Hu, D. C. Dowell, S. G. Benjamin, P. Hofmann, and H. Lin, 2012: Improvements in the analysis of the convective storm environment for the 2nd generation Rapid Refresh: Impact on RAP and nested HRRR forecasts. Recorded presentation, 26th Conf. on Severe Local Storms, Nashville, TN, Amer. Meteor. Soc., 7.5. [Available online at ams.confex.com/ams/26SLS/ webprogram/Paper212700.html.] 